\title{
Genetic Analysis of MMP Gene Polymorphisms in Patients With Kawasaki Disease
}

\author{
KAZUYUKI IKEDA, KENJI IHARA, KENICHIRO YAMAGUCHI, JUN MUNEUCHI, TAKURO OHNO, YUMI MIZUNO, \\ AND TOSHIRO HARA
}

\author{
Department of Pediatrics [K.I., K.Y., J.M., T.O., T.H.], Kyushu University, Fukuoka 812-8582, Japan; Fukuoka Children's Hospital and \\ Medical Center for Infectious Disease [Y.M.], Fukuoka 810-0063, Japan
}

\begin{abstract}
Kawasaki disease (KD) is an acute febrile disorder characterized by systemic vasculitis primarily occurring in coronary arteries. Matrix metalloproteinases (MMPs) have been considered to play pathophysiologic roles in the development of coronary artery lesions (CALs); therefore, an evaluation of the genetic contributions of the MMP genes to the development of CALs in KD patients would be beneficial for the prediction of CAL formation. We focused on the known functional single nucleotide polymorphisms (SNPs) in the $M M P$ genes (MMP-2-735C $>\mathrm{T}, M M P-3-1612$ 5A/6A, MMP-9$1562 \mathrm{C}>\mathrm{T}, M M P-12-82 \mathrm{~A}>\mathrm{G}$, and $M M P-13-77 \mathrm{~A}>\mathrm{G}$ ) and performed the association study between these SNPs and CAL formation in KD. The study population consisted of 44 KD patients with CALs and 92 without CALs and 175 healthy controls. As a result, allele and genotype frequencies of $M M P-13-77 \mathrm{~A}>\mathrm{G}$ showed significant differences between KD patients with CALs and without CALs ( $p=$ 0.00989 and $p=0.00551$, respectively). The estimated frequencies of the G-C haplotype in the MMP-13 gene promoter were significantly lower in KD patients with CALs than in those without CALs. There was no association between other MMP genes and CAL formation. In conclusion, the genetic evaluation by association study demonstrated that the $M M P-13$ gene, at least in part, contributed to the development of CALs in KD. (Pediatr Res 63: 182-185, 2008)
\end{abstract}

$\mathrm{K}$ awasaki disease $(\mathrm{KD})$ is an acute febrile disorder characterized by systemic vasculitis predominantly occurring in infants and young children. Although the administration of i.v. immunoglobulin (IVIG) in the acute phase of the disease significantly reduces the development of coronary artery lesions (CALs), $2 \%-15 \%$ of KD patients still suffer from this complication $(1,2)$. There is a strong inflammatory predilection for the coronary arteries, and the inflammation in subendothelial layers includes striking edema and infiltration of CD8 + T cells, monocytes, and macrophages with little or no fibrinoid necrosis and few polymorphonuclear cells (3). Inflammatory cells infiltrating from the lumen and from the adventitia to the media appear to mediate transmural damage to the arteries, followed by the development of coronary aneurysms.

The inability to obtain affected coronary arteries has precluded a comprehensive understanding of the mechanism how the pathologic changes in the vessel wall evolve. As a substitute for

Received June 7, 2007; accepted September 11, 2007

Correspondence: Kazuyuki Ikeda, M.D., Department of Pediatrics, Graduate School of Medical Sciences, Kyushu University, 3-1-1 Maidashi, Higashi-ku, Fukuoka 812-8582, Japan; e-mail: ikeq@ pediatr.med.kyushu-u.ac.jp

This work was supported by a Grant-in Aid for Scientific Research from the Ministry of Education, Culture, Sports, Science, and Technology of Japan. pathologic evaluation of the affected tissues, the measurements of cytokines in serum and gene expression levels in peripheral blood cells were studied for the prediction of CAL formation (4). In previous studies, serum vascular endothelial growth factor (VEGF) and hepatocyte growth factor levels in patients with KD were remarkably high in the acute phase and were major risk factors for the occurrence of CALs, probably by an increasing permeability in vessels to cause vascular edema (4-6). A significant elevation of serum matrix metalloproteinase (MMP)-9 levels and a remarkably high expression of the MMP-9 mRNA in the leukocytes were detected during the acute phase of KD (7), suggesting that MMP-9 may play a critical role in the coronary aneurysm formation.

Genetic predisposition to the development of CALs in KD has also been elucidated in various genetic backgrounds, and we previously found that the $V E G F$ gene and its receptor $K D R$ gene contributed to the development of CALs in KD patients (8-10). We recently found that tissue inhibitor of metalloproteinases 2 (TIMP2) was expressed at higher levels in peripheral blood mononuclear cells in KD with CALs than in those without CALs by cDNA microarray assay. Furthermore, the polymorphisms in the promoter region of the TIMP2 gene were genetically associated with CAL development in KD (11). Park et al. (12) reported that KD patients with CALs had a slightly higher frequency of the MMP-3-1612 6A allele and of the combined genotype of the MMP-3-1612 6A/6A and the MMP-9-1562 C/C, than those without CALs. Other SNPs with functional significances in the MMP gene family have not been evaluated.

The aim of this study was to assess the genetic contributions of the $M M P$ genes to the development of CALs in the KD patients. We focused on the known functional SNPs in the MMP genes (MMP-2-735C $>\mathrm{T}, M M P-3-1612$ 5A/6A, MMP-9-1562C $>\mathrm{T}$, $M M P-12-82 \mathrm{~A}>\mathrm{G}, M M P-13-77 \mathrm{~A}>\mathrm{G}$ ) and performed an association study of the SNPs between KD patients with and without CALs and controls (13-15). To characterize the genetic association between the $M M P-13$ gene and CAL formation in KD more fully, we evaluated the haplotype frequency of the $M M P-13$ gene in the promoter region between the groups.

\footnotetext{
Abbreviations: CALs, coronary artery lesions; IVIG, i.v. immunoglobulin; KD, Kawasaki disease; MMP, matrix metalloproteinase; TIMP2, tissue inhibitor of metalloproteinases 2
} 


\section{METHODS}

Patients and controls. The KD patients who were admitted to the Kyushu University Hospital or its affiliated hospitals between 1991 and 2003 were enrolled in this study. All patients met the criteria for the diagnostic guidelines of Kawasaki disease (http://www.kawasaki-disease.org/diagnostic/ index.html). A CAL was defined as the lumen diameter being at least $3 \mathrm{~mm}$ ( $4 \mathrm{~mm}$ in cases of the patients' age older than $5 \mathrm{y}$ ) or the internal diameter of one or more segments at least 1.5 times larger than that of the adjacent normal-size segments (16). Informed consent was obtained from patients or their parents. The study population consisted of $44 \mathrm{KD}$ patients with CALs ( 31 males and 13 females) and 92 without CALs ( 60 males and 32 females) and 175 normal school children without any history of KD. All patients received IVIG and oral aspirin $(30 \mathrm{mg} / \mathrm{kg} / \mathrm{d})$. This study was approved by the Ethical Committee of Kyushu University.

Genotyping. Genomic DNA was extracted from whole blood leukocytes with QIAamp Blood Kit (Qiagen, Tokyo, Japan).

Genotyping of the polymorphism MMP-2-735C $>\mathrm{T}$ (rs2285053) and $M M P-9-1562 C>T$ (rs3918242) was performed by the polymerase chain reaction-restriction fragment length polymorphism (PCR-RFLP) method. The

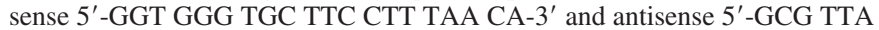
GAG ACG TTG GAA CC- $3^{\prime}$ primers for the $M M P-2-735 \mathrm{C}>\mathrm{T}$, and sense 5'-AAT GCC TGG CAC ATA GTA GG-3' and antisense 5'-ACT CCT TTC TTC CTA GCC AG-3' primers for the $M M P-9-1562 \mathrm{C}>\mathrm{T}$ were used to generate PCR products of $297 \mathrm{bp}$ and $481 \mathrm{bp}$, respectively. Three genotypes were distinguished as CC (95 and 202 bp), CT (95, 202, and 297 bp), and TT (297 bp) by restriction analysis with Sau 96I (New England Biolabs Inc., Beverly, MA) for the MMP-2-735C > T, and as CC (481 bp), CT (230, 251, and $481 \mathrm{bp}$ ), and TT (230 and $251 \mathrm{bp}$ ) by $S p h \mathrm{I}$ restriction for the MMP-9$1562 \mathrm{C}>\mathrm{T}(17)$.

The polymorphisms $M M P-3-16125 \mathrm{~A} / 6 \mathrm{~A}(\mathrm{rs} 3025058), M M P-12-82 \mathrm{~A}>\mathrm{G}$ (rs2276109), $M M P-13-77 \mathrm{~A}>\mathrm{G}$ (rs2252070), and $M M P-13-3343 \mathrm{C}>\mathrm{G}$ (rs675392) were analyzed by the TaqMan SNP Genotyping Assays using ABI PRISM 7700 Sequence Detection System (Applied Biosystems, Tokyo, Japan).

Haplotype estimation. For the supplementary evaluation of the MMP-13 gene, haplotype blocks were estimated between the two SNP sites using estimating haplotype frequencies $(\mathrm{EH})$ software program (http://www.linkage. rockefeller.edu/ott/eh.htm) individually in the patients and control groups. LD coefficients, $\mathrm{D}^{\prime}=\mathrm{D} / \mathrm{Dmax}$ (or $\mathrm{D} / \mathrm{Dmin}$ if the $\mathrm{D}^{\prime}$ value is negative) were calculated for pairs of alleles between the two sites of polymorphisms in the patients or controls using the method as previously described (18).

Statistical analysis. Genotype and allele distributions were analyzed by $\chi^{2}$ analysis with $2 \times 2$ and $2 \times 3$ contingency tables, respectively, using standard statistical software. For the multiple comparisons of the allele, genotype, and estimated haplotype frequencies in the MMP genes, Bonferroni's multiple adjustments were made to the level of significance, which was set at $p<$ 0.0166 for genotypes, alleles, and estimated haplotypes.

\section{RESULTS}

Polymorphisms in the MMP-2, -3, -9, -12, and 13 genes. As shown in Table 1, minor allele frequencies of $M M P-2,-3$, -9 , and -13 gene polymorphisms were $0.28,0.14,0.17$, and 0.45 , respectively, whereas that of the $M M P-12$ gene polymorphism was as low as 0.02. All the genotype frequencies of the analyzed SNPs in the control groups were in HardyWeinberg equilibrium. The distribution of $M M P-13-77 \mathrm{~A}>\mathrm{G}$ genotypes was significantly different between KD patients with CALs and those without CALs $(p=0.00551)$ and the frequency of A allele was significantly higher in KD patients with CALs than in those without CALs and controls $(p=0.00989$ and $p=$ 0.0147 , respectively). None of the allele or genotype frequencies of the $M M P-2,-3,-9$, and -12 gene polymorphisms showed significant differences between KD patients with CALs, those without CALs, and controls. Then, these frequencies of MMP gene polymorphisms were compared between total $\mathrm{KD}$ patients and controls, and we did not find significant differences in any SNPs between them $(p>0.1)$.
Haplotype analysis. In the MMP-13 gene, we analyzed two SNPs (rs2252070 and rs675392) in the promoter region. Three haplotypes with frequencies of more than 0.13 were estimated in the MMP-13 gene. These haplotypes accounted for about 99\% of all haplotypes in both KD patients and controls. The $\mathrm{D}^{\prime}$ value was greater than 0.9 between two SNPs. As shown in Table 2, the frequencies of the estimated haplotype of G-C were significantly lower in KD patients with CALs than in those without CALs $(p=0.0155)$.

\section{DISCUSSION}

MMPs are family members of zinc-dependent proteinases, degrade extracellular matrix (ECM) and basement membrane proteins, such as collagen and elastin, and play important roles in the expansion and aggression of cancer cells as well as in the development and progression of atherosclerosis (19). Imbalances between MMPs and their inhibitors TIMPs can result in pathologic matrix degradation of cartilages or bones in rheumatoid arthritis, membranous tissues in aortic aneurysms, or cancer-affected tissues (20-22). In KD, it is possible that inflammatory cells migrate into vascular lesions and produce a large amount of MMPs, and then excreted MMPs play major roles in the development of cardiovascular complications. Actually, MMP-2 and MMP-9 were highly expressed in acute KD aneurysms and the plasma MMP-9 level was significantly increased in KD patients with CALs $(23,24)$; hence, high expression of MMPs might be related to coronary arterial wall destruction and CAL formation in patients with KD. In addition, we recently found that the TIMP2 overexpression and the TIMP2 promoter polymorphisms were significantly associated with the development of CALs (11). Although TIMPs inhibit MMP activity, a line of evidence has indicated that TIMP2 accelerates activation of pro-MMP-2 $(25,26)$. Gavin et al. (24) reported a significant increase in TIMP2 expression in the adventitia of aneurysmal and nonaneurysmal coronary arteries, predominantly in infiltrating mononuclear cells in KD, which suggests an important role of these genes in the pathogenesis of arteritis in KD. In the present study, we analyzed the reported functional polymorphisms in the promoter regions of the $M M P$ genes related to the development of an aneurysm, and we found that $-77 \mathrm{~A}>\mathrm{G}$ polymorphism in the MMP-13 gene promoter had a significant association with the development of CALs. This polymorphism was genetically associated with atherosclerosis in a black male population, and the $\mathrm{A}$ allele of the $-77 \mathrm{~A}>\mathrm{G}$ polymorphism in the $M M P-13$ gene had transcriptional activity approximately twice as high as that of the G allele (27). MMP-13 has collagenolytic activity and is abundantly expressed in atherosclerosis and aortic aneurysm lesions (28). Hence, the predisposition to high MMP-13 expression in arteries might contribute to coronary arterial wall destruction and CAL development in KD as well as progression of atherosclerosis. Furthermore, we found an association between the promoter haplotype of the $M M P-13$ gene and the development of CALs. Taken together, the present study suggests that the promoter polymorphisms in the MMP-13 gene might elevate the levels of MMP-13 expression 


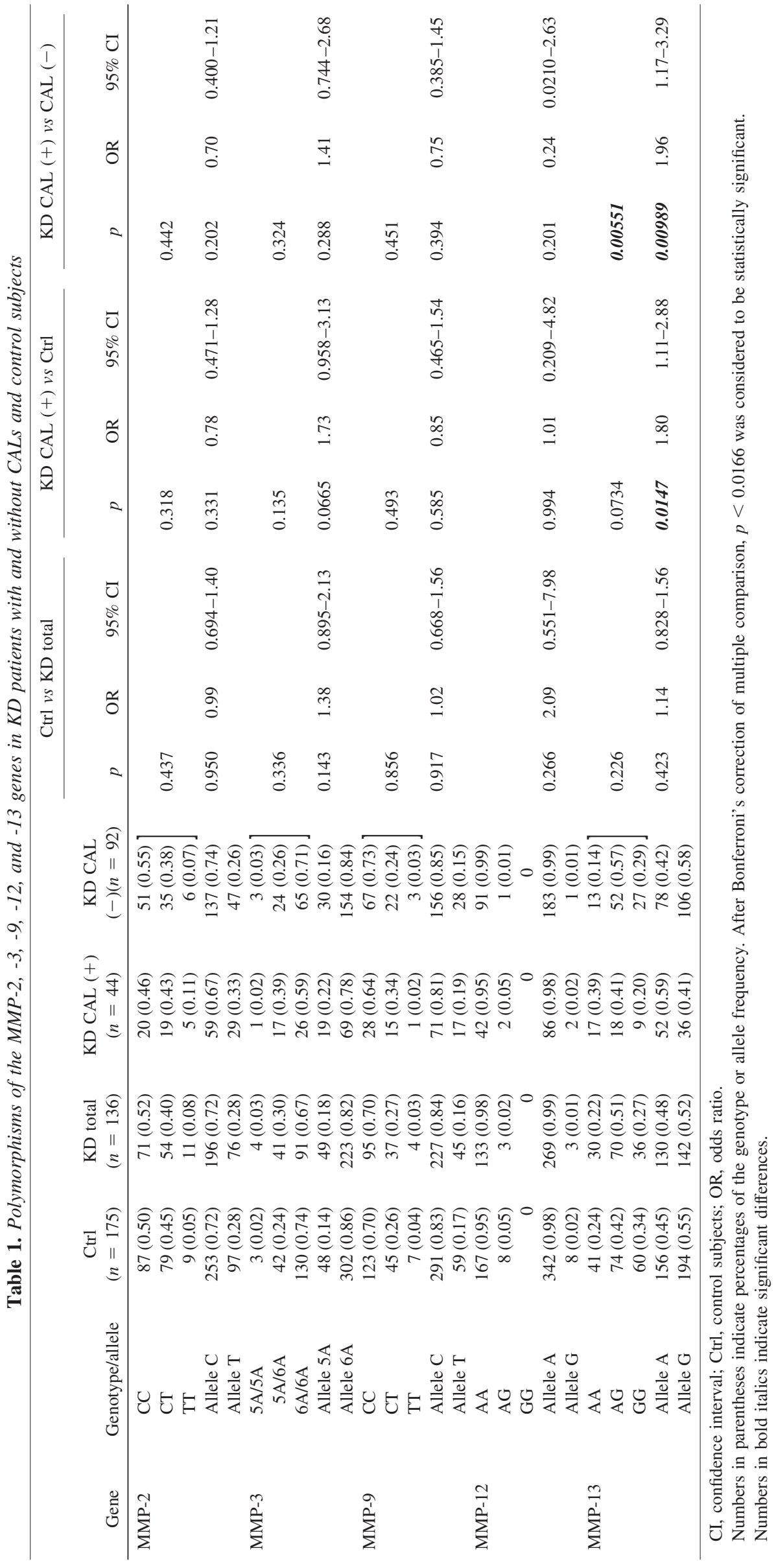


Table 2. Haplotype analysis of the MMP-13 gene in KD patients with and without CALs and controls subjects

\begin{tabular}{|c|c|c|c|c|c|c|c|}
\hline \multirow[b]{2}{*}{ Haplotype } & \multicolumn{4}{|c|}{ Estimated haplotype frequency } & \multicolumn{3}{|c|}{$p$} \\
\hline & $\begin{array}{c}\text { Ctrl } \\
(n=175)\end{array}$ & $\begin{array}{l}\text { KD total } \\
(n=136)\end{array}$ & $\begin{array}{c}\mathrm{KD} \operatorname{CAL}(+) \\
\quad(n=44)\end{array}$ & $\begin{array}{c}\text { KDCAL }(-) \\
(n=92)\end{array}$ & $\begin{array}{c}\mathrm{Ctrl} \\
\text { vs KD total }\end{array}$ & $\begin{array}{c}\mathrm{KD} \mathrm{CAL}(+) \\
\text { vs } \mathrm{Ctrl}\end{array}$ & $\begin{array}{c}\mathrm{KD} \mathrm{CAL}(+) \\
\text { vs CAL }(-)\end{array}$ \\
\hline $\mathrm{G}-\mathrm{C}$ & 0.548 & 0.518 & 0.395 & 0.576 & \multirow{3}{*}{0.542} & \multirow{3}{*}{0.0388} & \multirow{3}{*}{0.0155} \\
\hline A-G & 0.273 & 0.315 & 0.360 & 0.293 & & & \\
\hline $\mathrm{A}-\mathrm{C}$ & 0.169 & 0.163 & 0.230 & $0.130]$ & & & \\
\hline
\end{tabular}

The frequencies were estimated using the EH software program. After Bonferroni's correction of multiple comparison, $p<0.0166$ was considered to be statistically significant.

Number in bold italics indicates significant differences.

and cause a genetic predisposition to the development of CALs in KD patients.

In a previous report, $M M P-3$ and $M M P-9$ genes had a minor genetic effects on the development of CALs (12). It is possible that the differences in the genetic backgrounds or the study populations with respect to gender, age at $\mathrm{KD}$ onset, or variation of treatment protocol during the acute phase, will cause distinct results. There was a considerable difference in the male-to-female ratio of KD patients with CALs between our study and the previous research by Park et al. (12) (2.4 for ours versus 4.7 for that of Park et al.), whereas there was no difference in the age at KD onset. Details of treatment protocol during the acute phase were not provided in the paper by Park et al. (12). Further evaluation with a larger study population would be essential to confirm the genetic predisposition of the MMP-13 gene to the development of CALs in KD.

There are several limitations that need to be acknowledged and addressed regarding the present study. First, the sample sizes in this study did not have a sufficient power for statistical analysis of the $M M P-2,-3,-9$, and -12 genes. The minor allele frequencies of $M M P-2,-3,-9$, and -12 genes in the controls were as low as $0.28,0.14,0.17$, and 0.02 , respectively, and allele sizes of $\mathrm{KD}$ patients with and without CALs were only 88 and 184, respectively. In this situation, odds ratios of $1.92,2.04,2.09,8.72$, or greater were required to reach statistical significance between KD patients with and without CALs. Second, the estimated haplotype frequency in the $M M P-13$ gene could have been confirmed by information from their parental genotypes. Consequently, further evaluation with a larger study population and, if possible, with parental genotype information would give us more confirmatory results of this study.

In conclusion, our study has demonstrated that the MMP-13 gene appears to be a susceptibility gene to the development of CALs in patients with KD. Better understanding of the relationship between MMP-13 and vascular lesions in KD would contribute to the understanding of the mechanism of CAL formation in $\mathrm{KD}$.

\section{REFERENCES}

1. Durongpisitkul K, Gururaj VJ, Park JM, Martin CF 1995 The prevention of coronary artery aneurysm in Kawasaki disease: a meta-analysis on the efficacy of aspirin and immunoglobulin treatment. Pediatrics 96:1057-1061

2. Muta H, Ishii M, Egami K, Furui J, Sugahara Y, Akagi T, Nakamura Y, Yanagawa H, Matsuishi T 2004 Early intravenous gamma-globulin treatment for Kawasaki disease: the nationwide surveys in Japan. J Pediatr 144:496-499

3. Burns JC, Glode MP 2004 Kawasaki syndrome. Lancet 364:533-544

4. Maeno N, Takei S, Masuda K, Akaike H, Matsuo K, Kitajima I, Maruyama I, Miyata K 1998 Increased serum levels of vascular endothelial growth factor in Kawasaki disease. Pediatr Res 44:596-599
5. Ohno T, Igarashi H, Inoue K, Akazawa K, Joho K, Hara T 2000 Serum vascular endothelial growth factor: a new predictive indicator for the occurrence of coronary artery lesions in Kawasaki disease. Eur J Pediatr 159:424-429

6. Ohno T, Yuge T, Kariyazono H, Igarashi H, Joh-o K, Kinugawa N, Kusuhara K, Hara T 2002 Serum hepatocyte growth factor combined with vascular endothelial growth factor as a predictive indicator for the occurrence of coronary artery lesions in Kawasaki disease. Eur J Pediatr 161:105-111

7. Takeshita S, Tokutomi T, Kawase H, Nakatani K, Tsujimoto H, Kawamura Y, Sekine I 2001 Elevated serum levels of matrix metalloproteinase-9 (MMP-9) in Kawasaki disease. Clin Exp Immunol 125:340-344

8. Kariyazono H, Ohno T, Khajoee V, Ihara K, Kusuhara K, Kinukawa N, Mizuno Y, Hara T 2004 Association of vascular endothelial growth factor (VEGF) and VEGF receptor gene polymorphisms with coronary artery lesions of Kawasaki disease. Pediatr Res 56:953-959

9. Breunis WB, Biezeveld MH, Geissler J, Ottenkamp J, Kuipers IM, Lam J, Hutchinson A, Welch R, Chanock SJ, Kuijpers TW 2006 Vascular endothelial growth factor gene haplotypes in Kawasaki disease. Arthritis Rheum 54:1588-1594

10. Thornton S 2006 Contribution of angiogenic genes to the complex genetic trait underlying Kawasaki disease. Arthritis Rheum 54:1361-1365

11. Furuno K, Takada H, Yamamoto K, Ikeda K, Ohno T, Khajoee V, Mizuno Y, Hara T 2007 Tissue inhibitor of metalloproteinase 2 and coronary artery lesions in Kawasaki disease. J Pediatr 151:155-160

12. Park JA, Shin KS, Kim YW 2005 Polymorphism of matrix metalloproteinase-3 promoter gene as a risk factor for coronary artery lesions in Kawasaki disease. J Korean Med Sci 20:607-611

13. Ye S 2006 Influence of matrix metalloproteinase genotype on cardiovascular disease susceptibility and outcome. Cardiovasc Res 69:636-645

14. Ogata T, Shibamura H, Tromp G, Sinha M, Goddard KA, Sakalihasan N, Limet R, MacKean GL, Arthur C, Sueda T, Land S, Kuivaniemi H 2005 Genetic analysis of polymorphisms in biologically relevant candidate genes in patients with abdominal aortic aneurysms. J Vasc Surg 41:1036-1042

15. Yu C, Zhou Y, Miao X, Xiong P, Tan W, Lin D 2004 Functional haplotypes in the promoter of matrix metalloproteinase-2 predict risk of the occurrence and metastasis of esophageal cancer. Cancer Res 64:7622-7628

16. Akagi T, Rose V, Benson LN, Newman A, Freedom RM 1992 Outcome of coronary artery aneurysms after Kawasaki disease. J Pediatr 121:689-694

17. Wang Y, Fang S, Wei L, Wang R, Jin X, Wen D, Li Y, Guo W, Wang N, Zhang J 2005 No association between the $\mathrm{C}-1562 \mathrm{~T}$ polymorphism in the promoter of matrix metalloproteinase-9 gene and non-small cell lung carcinoma. Lung Cancer 49:155-161

18. Lewontin RC 1995 The detection of linkage disequilibrium in molecular sequence data. Genetics 140:377-388

19. Sternlicht MD, Werb Z 2001 How matrix metalloproteinases regulate cell behavior. Annu Rev Cell Dev Biol 17:463-516

20. Woessner JF Jr 1991 Matrix metalloproteinases and their inhibitors in connective tissue remodeling. FASEB J 5:2145-2154

21. Knox JB, Sukhova GK, Whittemore AD, Libby P 1997 Evidence for altered balance between matrix metalloproteinases and their inhibitors in human aortic diseases. Circulation 95:205-212

22. Stetler-Stevenson WG 1996 Dynamics of matrix turnover during pathologic remodeling of the extracellular matrix. Am J Pathol 148:1345-1350

23. Senzaki H, Masutani S, Kobayashi J, Kobayashi T, Nakano H, Nagasaka H, Sasaki N, Asano H, Kyo S, Yokote Y 2001 Circulating matrix metalloproteinases and their inhibitors in patients with Kawasaki disease. Circulation 104:860-863

24. Gavin PJ, Crawford SE, Shulman ST, Garcia FL, Rowley AH 2003 Systemic arterial expression of matrix metalloproteinases 2 and 9 in acute Kawasaki disease. Arterioscler Thromb Vasc Biol 23:576-581

25. Baker AH, Edwards DR, Murphy G 2002 Metalloproteinase inhibitors: biological actions and therapeutic opportunities. J Cell Sci 115:3719-3727

26. Karagiannis ED, Popel AS 2004 A theoretical model of type I collagen proteolysis by matrix metalloproteinase (MMP) 2 and membrane type 1 MMP in the presence of tissue inhibitor of metalloproteinase 2. J Biol Chem 279:39105-39114

27. Yoon S, Kuivaniemi H, Gatalica Z, Olson JM, Buttice G, Ye S, Norris BA, Malcom GT, Strong JP, Tromp G 2002 MMP13 promoter polymorphism is associated with atherosclerosis in the abdominal aorta of young black males. Matrix Biol 21:487-498

28. Mao D, Lee JK, VanVickle SJ, Thompson RW 1999 Expression of collagenase-3 (MMP-13) in human abdominal aortic aneurysms and vascular smooth muscle cells in culture. Biochem Biophys Res Commun 261:904-910 